\title{
CARTOGRAPHIC METHODS FOR LARGE SCALE GLACIER MAPS
}

\author{
by
}

\author{
Yin Shicong and Chen Jianming
}

(Lanzhou Institute of Glaciology and Geocryology, Academia Sinica, Lanzhou, China)

\begin{abstract}
Glacier mapping is steadily developing, along with the continuous expansion of glaciological research, in China. In the last 20 years we have made surveys and drawn up glacial topographic maps on large scales, of various study areas in Tianshan and the Qinghai-Xizang Plateau. This paper discusses the cartographic techniques, in the form of points, lines, symbols, brush-shading, colours, etc., used to create a vivid reproduction of the special natural landscape of glaciers on maps for the use of glaciologists and other scientists. For example, variations in rock symbols may be used to show the exposed bedrock, the glacial abrasion and the cryogenetic weathering. Different colours and points are used to indicate the various depositional landforms which are also enhanced by the method of brush-shading and the use of differently coloured contour lines. In addition, the paper discusses the technical and theoretical problems of glacier mapping.
\end{abstract}

\section{INTRODUCTION}

A glacier map is a special scientific map. It shows the geomorphological features of an alpine area covered by ice and snow. It not only provides the basic data for glaciological research, but also is a medium for showing the results. Glaciers developing on high mountains are produced by the cold climate; they, in turn, produce the special, glacial topography.

The main requirements of glacier mapping are: 1. Precision, so that accurate measurements can be taken from the map.

2. Authenticity, so that glacial geomorphological features can be portrayed accurately and objectively.

These considerations have been the subjects of research into glacier surveying and mapping for many years. The perfect glacier map should be based strictly on a mathematically accurate survey. It should show all glacial geomorphological features, not merely the static relief, but also the dynamic aspects, with such technical and artistic expression, in respect of points, lines, symbols, brush-shading, use of colours, etc., as to bring out the natural landscape of the glacier vividly before the eyes of glaciologists and scientists who use it.

\section{CONTOUR LINES}

Drawing contour lines from terrestrial photogrammetric survey data is a very good method (Wang Wenying, 1981) of showing glacial geomorphological forms in detail. Generally, the scale of a glacier map is between 1:10000 and 1:50000 and the best is 1:25000. Contour lines, drawn on such scales, should be drawn as accurately as possible; simplification by generalisation should be avoided. Occasionally, because of limitations of scale, one can accept a degree of simplification in order to depict a particular geomorphological feature.

For example: a glacial trough is U-shaped; the side of a glaciated valley steep and concave; horns and arêtes are sharply defined, with a "sawtooth" shape. When showing glacial movement, contour lines on a glacier tongue become very convoluted, but are arranged to show a convex form on the lower reaches of the glacier. In the firn basin, the contour lines show a concave shape, like an armchair. We use thinly or thickly spaced contour lines to show gentle or steep slopes; smooth and solid, winding irregular contour lines depict lithological character and the degree of cryogenetic weathering. To sum up, contour lines not only show a variety of geomorphological features, but also reflect the geometric precision of the map. They are the most basic draughting device of the glacier map.

\section{INDICATION OF EXPOSED BEDROCK}

The symbols for exposed bedrock not only increase the stereoscopic effect but can also vividly show the steepness, smoothness and lithological structure of the rock surfaces in the mountains. We use different groups of rock symbols to pick out the landforms produced by snow and ice erosion and cryogenetic weathering. In this way, horns, arêtes, nunataks and cirques, in a glacial area, are clearly differentiated and the grandeur of the scenery is revealed.

In the design of symbols, there are two important considerations (Yin Shicong, 1980). First, the geomorphological features, lithological character and weathering of the bedrock have to be understood. Clear photographs are essential for this. Secondly, when drawing the symbols on the map, they must be related to a light source (for example, we may imagine the light coming from the north-west) in order to achieve a stereoscopic effect. Thus, if a mountain has a sunny side and a shaded side, the stereoscopic effect is increased. The lithological character of bedrock is mainly shown up by the associated landforms, different rock types producing different forms. Thus, granite is hard and has no stratification, while during weathering its surface becomes broken; it is therefore drawn in hard and irregular symbols.

As an example of the method of showing the exposed bedrock, take the map of Mt Qomolangma (Fig.1).

Mt Qomolangma (Mt. Everest), at 8848 m. a.s.l., is the highest peak in the world, and shaped like a huge pyramid. Its peak is clear, but not sharp; its base is wide. Its northern slope is very steep and, because of strong winds, ice and snow cannot stay here. On the back walls of the firn basins, avalanches and ice falls are very frequent, producing many avalanche grooves. Mt Qomolangma is composed of metamorphic rocks, with a gentle dip to the north and a smooth surface. Terraces and steep cliffs are formed by ice and snow erosion and cryogenetic weathering of soft and hard bands in the rock. Ice and snow are distributed transversely, in parallel belts. All these features form an essential basis on which to design the symbols of exposed bedrock for the map of Mt Qomolangma.

When designing symbols, we should consider the light source. If we suppose the light to come from the north-west, to increase the steoroscopic effect, then the north-west side of the mountain, facing the light, is drawn in with fine lines and south-east, or shaded side with heavier lines. However if the slopes are steep on the sunny side, brush-shading is used to show up the grooves with stereoscopic effect (Fig.1,B).

Above $7000 \mathrm{~m}$ a.s.l., on Mt Qomolangma, the metamorphic rocks are stratified. Here, we use transverse lines to show wide, smooth surfaces and oblique or vertical lines to depict broken or steep surfaces. Crevasses are shown by a break in the symbols or lines, while snow accumulation is indicated by white colour. The symbols 


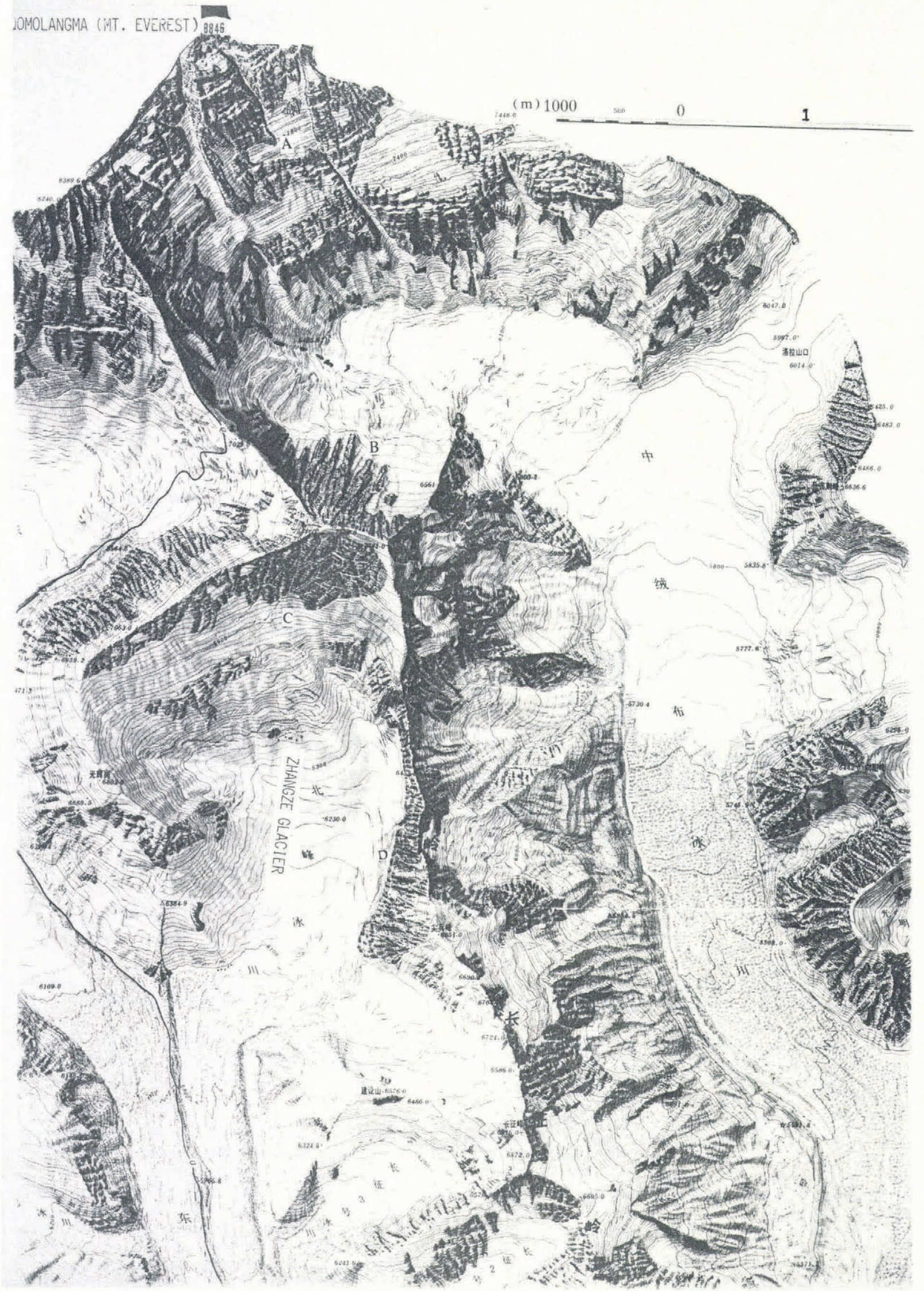

Fig.1. Distribution of the exposed bedrock on the northern slope of Mt. Qomolangma. 
defining the landforms of the bedrock create a "true-to-life" effect.

At the back wall of the Zhangze Glacier basin, the rocks are stratified and have a gentle slope, dipping to the north. The slope between 7000 and $7500 \mathrm{~m}$ a.s.l. has suffered abrasion by ice and snow for a long time. The rock surface is smooth, with crevasses full of snow and ice, like a white net. The bedrock symbols are here drawn with lines parallel to the contours, with snow patches left white (Fig.1,C).

The right-hand rock wall of the Zhangze Glacier (Fig.1,D) is steep, with arêtes and avalanche grooves on the upper part and a smooth surface with glacial striae on the lower part. The smooth surface tells us that the Zhangze Glacier was larger and thicker in the past. Since then the glacier has retreated and thinned. We use hard lines, parallel to the direction of glacier motion, to show this and to show that this part of the glacier is separate from the area of jagged rocks on the upper slope.

The rock symbols around Mt Zhangze, south of the Zhangze Glacier, mainly show features of the steep south slope and gentler north slope, as well as the structure, with its dip to the north, so that the horn stands out more clearly. In Fig.2, a north-facing cirque of the West Rongbu Glacier is well shown by a similar use of symbols.

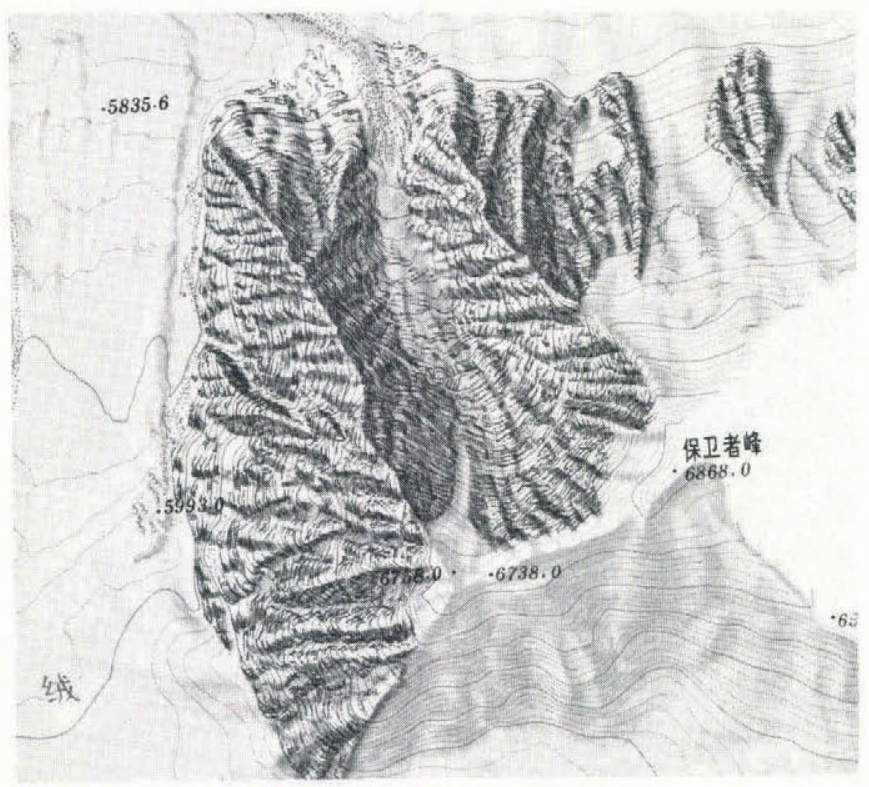

Fig.2. The cirque on the north of West Rongbu Glacier.

\section{USE OF POINT MARKS}

The various, coloured point marks or symbols are used to show the genetic type, material, and landforms of soft deposits.

1. We use smoky, grey points to show glacial deposits, and, by varying their form, distribution and location, to identify new moraines, old till and fluvioglacial deposits. The streamlined, dense points on supraglacial areas identify medial and lateral moraines and supraglacial debris, thus indicating the direction of glacier movement. Dense points pick out the long moraines and supraglacial moraine hills alternating with depressions in the middle/lower glacier section. The arched, dense points at the glacier terminus show the end moraine.

The main consideration, in using this group of point marks, is to enhance the stereoscopic effect, areas of scattered and densely-packed points showing the shaded and sunny slopes, respectively. Secondly, the number of points, more or less, reflects the quantitative difference between the deposits (Yin Shicong, 1982). On the map of the Mt Tomur region, the old moraines, far from the existing glaciers, are differentiated by location. For example, the technical moraine of the "Pochengze" Glaciation, at the outlet of the Muzat river, is clearly made up of many arched moraines. The distance between the two middle arched moraines is the

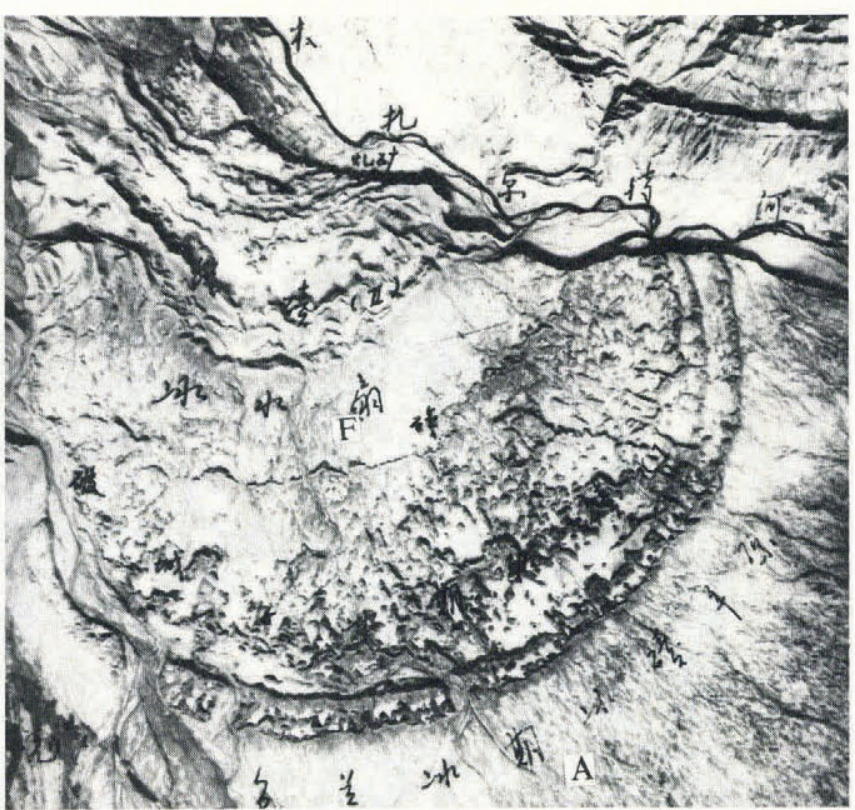

Fig.3. The arched end moraines of Pochengzi glaciation on the outlet of Muzat river, Tianshan (air photo).

longest and, here, there is a fluvioglacial fan plain (Fig.3,F). We use dense and scattered points to show the moraine and fluvioglacial fan plain, respectively. But the till from the "Keziblak" (Riss) period, outside the arched moraines, forms a fluvioglacial fan plain with some boulders on its surface, and, here, we use scattered points in a special fan-shaped pattern to show the plain whilst among them a few heavy black points represent the boulders (Fig.4,A).

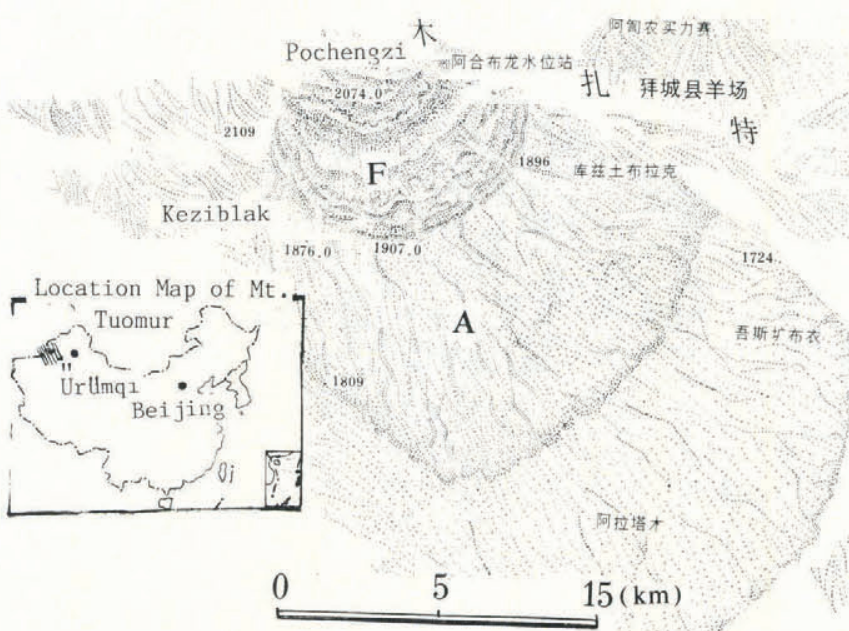

Fig.4. The point marks of the arched end moraines and fluvio-glacial fan of Pochengzi glaciation (Würm) as well as moraine plain of Keziblak glaciation (Riss).

2. We use heavy brown points to indicate slopes, pluvial and alluvial deposits, and dunes. Their distribution and forms represent different genetic types. For example, in showing slope deposits on the middle to lower parts of steep slopes, the points are distributed in a downward direction on the slope, gradually becoming larger to show the landforms of the debris skirt and the gravitational grading, with fine debris above and coarser deposits below.

To indicate the forms of pluvial and alluvial fans in the outlets of large rivers, we distribute the points in fan shapes. The dunes, sand ridges and sand domes, formed by wind action, are picked out by denser points in the shapes of crescents, ridges and circular cones.

3. The blue points on the map indicate slope, while blue points arranged in lines mark the average firn lines on glaciers. 


\section{THE BRUSH-SHADING METHOD}

The principal current method of showing landforms and topography on maps is by means of contour lines, but a shortcoming of this method is its lack of stereoscopic effect. The method of brush-shading is based on the ability of light and shadow to create shapes and uses direct, oblique, and comprehensive lighting to create a kind of stereoscopic effect when superimposed on a basic contour map. Thus, it can enhance the image of the relief objectively and make it easy to read. On the topographic map of Mt Qomolangma on the scale of 1:25000, brush-shading is a very successful way to show ice pyramids. Another example is seen on the Batura Glacier map, on a scale of 1:60000, where brushshading is used to show the ice ogives. As the velocity of glacier movement increases from the formation area downwards, the curvature of the ogives gradually increases (Wang Yimou, 1980). A crescent-shaped, wave ogive is drawn by brush-shading with soft, half-colouring, which gradually becomes lighter down the glacier. The top of the ogives is more arched in a downward direction, also showing the movement down the glacier.

\section{COLOURS ON THE MAP}

The variations in colour used in glacier maps are very important. Since the depiction of ice, snow and severe cold is the main feature of such a map, printed colours should be cold ones. Contour lines of glaciers and snow slopes are printed in blue, while those of ice-free slopes are brown-red and those of exposed bedrock are brown. The colours used in brush-shading should be as close as possible to the colours of the natural landscape, so that bedrock, debris-slope, ice, snow, vegetation, etc., are all differentiated. The colours also reflect the features of the local climate. In printing, the black and white strokes of the brush-shading are usually divided between two printing plates so that the two plates, i.e. the blue plate (heavy contrast) and the grey plate (light contrast) will, when superimposed during printing, produce a blue-grey colour, giving an impression of coldness.

\section{REFERENCES}

Shi Zhuhui 1983 Method of geomorphic brush-shading, surveying and mapping. Beijing, Survey Press.

Wang Wen-Ying, Ch'en Chien-Ming 1980 Terrestrial stereophotogrammetric surveying and mapping in the region of Mount Qomolangma and the Batura glacier in Karakoram. By Wang Wenying and Chen Jianming. Journal of Glaciology and Cryopedology 2(4): 22-28

Wang Yimou, Peng Qilong, Feng Yusun 1980 The cartographic methods of the map of Batura glacier: the expedition and research of the Batura glacier. Karakoram mountains. Beijing, Science Press: 221-228

Yin Shicong 1980 Method of showing naked bedrock on the glacial map scale 1:25000 of Mt. Qomolanga. Journal of Glaciology and Cryopedology 2 (Special issue): 74-76

Yin Shih-Ts'ung, Wu Huan-Chung 1982 Compilation of 1:200000 maps of "Glacial topography of Tumor Peak district" and "Glacial geomorphology of Tumor district" in Tianshan. By Yin Shicong and Wu Huanzhong. Journal of Glaciology and Cryopedology 4(2): 89-92

Editor's note: Titles quoted above are English versions of the original Chinese. 